\title{
An Attempt of Screw Driving Sounding Test in Malaysia
}

\author{
Aminaton Marto ${ }^{1, *}$, Go Sakai ${ }^{2}$, Naoaki Suemasa ${ }^{3}$, and Nadiah Jamaludin ${ }^{4}$ \\ ${ }^{1}$ Disaster Preparedness and Prevention Centre, Malaysia-Japan International Institute of Technology, \\ Universiti Teknologi Malaysia, Jalan Sultan Yahya Petra, 54100 Kuala Lumpur, Malaysia \\ ${ }^{2}$ Japan Home Shield Corporation, Ryogoku City Core 17F, 2-10-14 Ryogoku Sumuda-Ku, Tokyo \\ 130-0026, Japan \\ ${ }^{3}$ Department of Urban and Civil Engineering, Tokyo City University, Setagaya-ku, Tokyo 158-8557, \\ Japan \\ ${ }^{4}$ Faculty of Civil Engineering, Universiti Teknologi Malaysia, 81310 UTM Johor Bahru, Johor, \\ Malaysia
}

\begin{abstract}
Conventional soil investigation methods such as Mackintosh Probe Test (MPT) have limitations, e.g., require manual work for the equipment and data accuracy is low due to human error. While Standard Penetration test (SPT) needs high skilled workers and the cost per testing is expensive. Hence, Screw Driving Sounding test (SDS) was developed in Japan as a solution to the aforementioned disadvantages. An attempt was done to implement this test in Malaysia at different types of soils. This paper presents the results obtained from Batu Pahat and Cheras sites. Data from SDS tests were compared with the existing data of SPT and MPT available from Batu Pahat and Cheras sites, respectively. Results of the coefficient of determination, $\mathrm{R}^{2}=0.721$ for Batu Pahat Site and 0.851 for Cheras Site illustrate that the SPT and MPT results are highly correlated with SDS test results. From this preliminary findings, it shows that SDS test has the potential for soil characterizations in soil investigation work in Malaysia.
\end{abstract}

\section{Introduction}

Soil investigation is crucial in the construction process and it needs to be done in preliminary work. However, the conventional method is cumbersome due to time consuming and high cost. Therefore, with the advancement of technology; the use of in-situ soil testing has increased in geotechnical engineering practice in order to provide economical alternatives.

In conjunction with the above, there are several in-situ soil testing available for characterization of soils. For instances, the most commonly tests are Standard Penetration Test (SPT), Cone Penetration Test (CPT), Mackintosh Probe Test (MPT), Piezo-cone $(\mathrm{CPTu})$, Swedish weight sounding (SWS), flat dilatometer (DMT), pressure meter test (PMT), and vane shear test (VST). Each test applies specific loading patterns to measure

\footnotetext{
*Corresponding author: aminaton@utm.my
} 
the corresponding soil response in an attempt to evaluate material characteristics, such as strength and/or stiffness (AASHTO, 1988). Soil investigation needs to obtain the exact and precise condition of the subsurface soils in a particular site or area. Conventional soil investigation methods have been the sources for these data as it has been proven reliable.

Standard Penetration Test (SPT) was established to provide geotechnical engineering properties for foundation design purposes. SPT measures the resistance to penetration which offered by soil at various depths. In addition, the test was initially designed to determine the relative density of cohesionless soils. Nowadays, the test has been improved from its previous state which includes the design of foundations by determining the load and the required embedment of piles into the bearing strata [1]. In other words, SPT test is carried out within a borehole and the results can be used to determine relative density, bearing capacity, settlement of granular soil and to correlate the approximate strength of cohesive soil.

There are several limitations of SPT in engineering soil investigation such as lack of repeatability, no continuous soil profile and the SPT blow count is dependent on soil type, particle size, and the age and stress history of the deposit [2]. This test requires more manpower to conduct such as it needs at least one person conduct the machine, one person to jot down the bore log, and one person to maintain the water supply for the machine to work. Moreover, more resources are needed, such as time and money in order to complete one test.

The Mackintosh Probe is a lightweight device, which can be conveniently used for the investigation of soft soil down to depth of $10 \mathrm{~m} \mathrm{[3].} \mathrm{It} \mathrm{was} \mathrm{developed} \mathrm{for} \mathrm{the} \mathrm{investigation}$ of peat and has been used in a variety of soft soils [4]. According to [5], Mackintosh Probe has been practically implemented in the residual soils of Malaysia. Residual soils are commonly the soils from the disintegration and weathering of sedimentary rocks which contained mostly of siltstone and shale.

Several limitations of the Mackintosh Probe is that it is not suitable to be used in hard or gravelly soils or cobbles. This is due to its relatively low energy hammer used to drive the probe into the ground [3]. Besides that, MPT also faces a disadvantage of human error due to miscalculation during conducting the test.

The Screw Driving Sounding test (SDS) has been recently developed in Japan as the improved version of SWS. The development of SDS is to reduce the drawbacks of the SWS with the integration of rod friction estimation. Moreover, SDS method is simple, fast, only need small working area, and the test is also cheap when compared with other soil investigation method/equipment. Not just that, the data from the machine could be sent to the 'cloud' and would be later downloaded from the G-web for an analysis [6]. Once results are sent to the 'cloud', anyone with the given password could access to the analysed data. While the test crew is still at the site, by looking the results one could instruct them to do more tests at any other location due to some questionable results. This is the technology in line with the Industrial Revolution 4.0 that is by using automation in work and making use of the cloud computing technology.

Swedish Weight Sounding (SWS) is one of the soil investigation test that is popular in Japan and Nordic countries and were used in East Europe countries, Singapore and Algeria $[6,7]$. In Sweden, 20,000 SWS tests were done annually 8]. SWS was used in Japan to identify the performance level of housing lots [9]. This is due to the system being simple, easy and fast in terms of procedure. Moreover, it is cost efficient and could provide a continuous soil profile, similar to CPT [6]. However, this equipment is not commonly used in Malaysia and other Southeast Asian countries.

SWS also has a few disadvantages such as low accuracy in soil classification [9]. This is due to the result of SWS being influenced by the rod friction. As the rod friction increase, the penetration load, number of half turns, and soil resistance will be over-estimated 
especially if the soil contains gravel [10]. This SWS test does not provide soil sampling, thus, classification of soil is done by going through the test results, condition on site and also checked by experienced test examiner. SWS classifies soil such as organic soil, clay, silt, and loam as cohesive soil [9]. Moreover, SWS could not penetrate into dense soil and the depth of penetration is usually within 10-15 m [10]). Thus, SDS was built to improve the weaknesses of SWS.

It is anticipated that there is a strong potential of this SDS equipment to be used widely in Malaysia since SDS can contribute to quality, safety \& professionalism and productivity in the Malaysia Construction Industry Transformation Programme (CITP) 2016-2020. This paper presents the results obtained from SDS tests, carried out at two different sites in Malaysia and compared with the existing data of SPT and MPT available from the sites. This is the first attempt of using SDS in site investigation work in Malaysia.

\section{Testing procedure}

SDS equipment and procedure had been explained widely by previous researchers [6, 9-11]. Basically, in carrying out the test SDS uses 7 number of load steps and the rod would penetrate the soil layer continuously at the rate of $25 \mathrm{rpm}$. The 7 load steps for SDS are $0.25,0.38,0.50,0.63,0.75,0.88$ and $1 \mathrm{kN}$. The load was increased for every revolution of the rod. For each $25 \mathrm{~cm}$ penetration, the rod would move up about 1 to $2 \mathrm{~cm}$ and rotate to calculate the rod friction. As explained by [6], this process is done in an automatic manner. The parameters measured by SDS machine are maximum torque $\left(T_{\max }\right)$, average torque ( $T_{\text {avg }}$ ) and minimum torque on rod $\left(T_{\min }\right)$, penetration length $(\mathrm{L})$, penetration velocity $(\mathrm{V})$ and number of rotations $(\mathrm{N})$. Both load and torque are applied to the rod at the same time during the SDS test. Plasticity model had been used in analysing the SDS data, as described by [2].

As an attempt to determine if SDS can be used to provide soil characterizations and site profiling in Malaysian soil and geology, 10 sites around Johor, Kuala Lumpur and Selangor had been chosen. Those are the sites for either road, building or other geotechnical engineering projects. The sites are comprised of various types of soil and formation. Results of SPT and laboratory tests of deep boring investigation as well as the MPT results from the Site Investigation Reports of respective boreholes from the selected sites were analysed and used to compare with the SDS results. For this paper however, only the results from Batu Pahat, Johor and Cheras, Selangor sites are evaluated as a preliminary effort to see if SDS data could be correlated with the SPT and MPT data based on the value shown by the coefficient of determination, $\mathrm{R}^{2}$. If so, SDS shall be considered to be used as an alternative and potential method in site investigation work in Malaysia. Figure 1 shows the SDS equipment that has been use for tests in several selected sites in Malaysia.
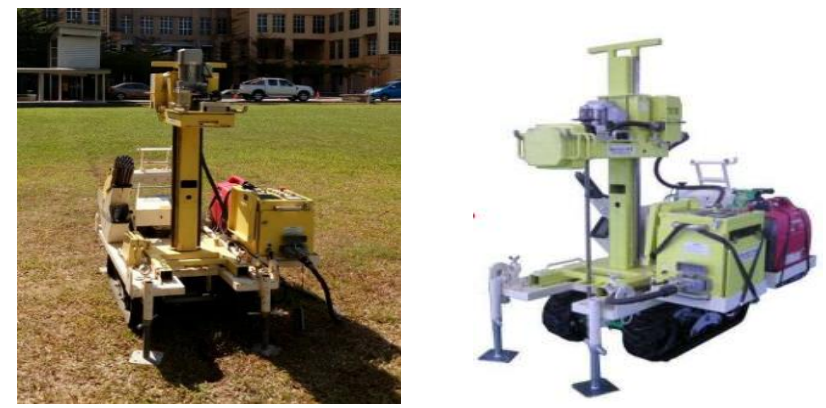

Fig. 1. Screw driving sounding (SDS) equipment used for tests in several selected sites in Malaysia 


\section{Results and discussions}

At Batu Pahat site in Johor, three SDS tests were carried out and the results are compared with the results of SPT from two boreholes. SDS points were carried out within $1.5 \mathrm{~m}$ of the existing borehole in order to maintain the accuracy of the compared data. Figure 2 shows the location of SDS and SPT points in Batu Pahat, Johor. Meanwhile, two SDS tests data from Cheras, Selangor site were compared with available nearby MPT data. Figure 3 shows the location of SDS and MPT points in Cheras.

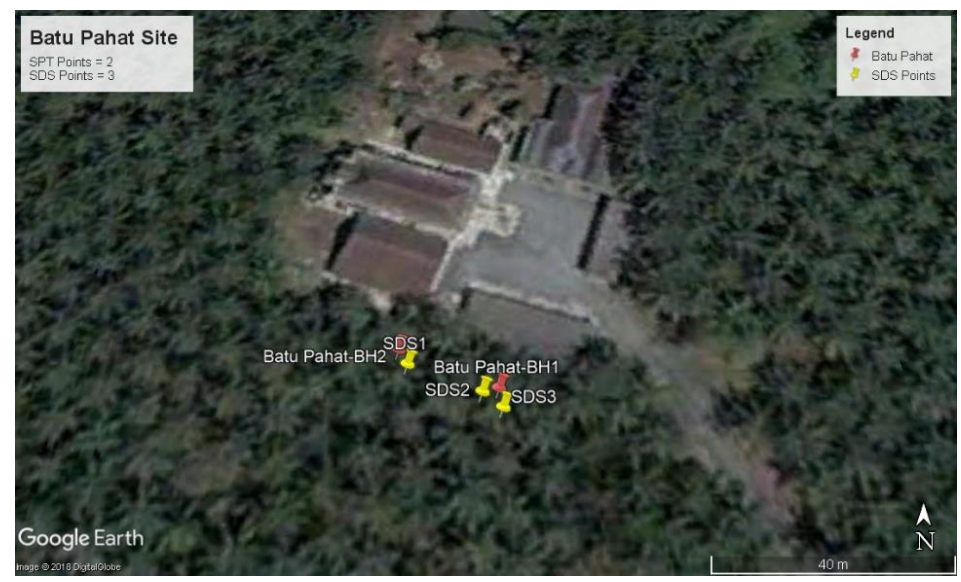

Fig. 2. Locations of Borehole and SDS points at Batu Pahat site

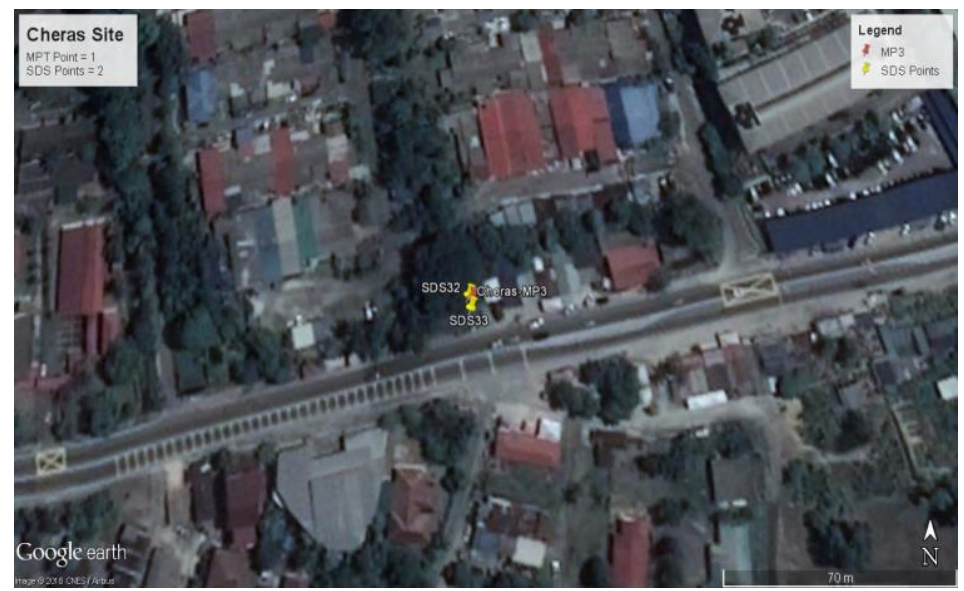

Fig. 3. Locations of MPT and SDS points at Cheras site

\subsection{Correlation between SDS and SPT}

For Batu Pahat site, analysis were carried out between data from SDS results with SPT-N values only since there was no existing MPT results available. Average of corrected torque obtained at every $25 \mathrm{~cm}$ penetration from SDS1, SDS2 and SDS3 tests was calculated and plotted against the depth. Figure 4 shows the SDS results and the soil profile obtained from 
the borelogs of Site Investigation (SI) report (carried out by the local SI contractor) for Borehole 1 (BH1) and Borehole 2 (BH2).

SI report shows that the Topsoil of thickness $1.5 \mathrm{~m}$ overlaid the soils in BH1 and BH2. The soil profile for BH1 consists of soft Sandy SILT from $1.5 \mathrm{~m}$ until $10.5 \mathrm{~m}$ with SPT-N values of 2 to 4 . From $10.5 \mathrm{~m}$ to $13.5 \mathrm{~m}$, the soil layer is still Sandy SILT but it can be considered as stiff, with the SPT-N values of 13 to 16 . Beyond $13.5 \mathrm{~m}$ depth the soil is classified as Silty SAND with SPT-N values greater than 14. BH2 comprised of a very soft Clayey SILT layer from $1.5 \mathrm{~m}$ until about $9 \mathrm{~m}$ with SPT-N values of 1 but increased to 13 at $9 \mathrm{~m}$ depth. Between $9 \mathrm{~m}$ to $12 \mathrm{~m}$ depth, the encountered soil layer is classified as stiff Sandy SILT with SPT N-value varies between 13 and 16. Beyond $12 \mathrm{~m}$ depth, the soil layer is classified as a very stiff gravelly Sandy SILT.

In determining the correlations between SDS and SPT, the authors focussed on the corrected torque variations for different types of soil layers as also been done before by [10] and [11]. As anticipated, different soil layers have different values of corrected torques. From Figure 4, it could be deduced that the variations of corrected torque is large for stiff soils as shown in Figure 4(b). Other than that, silt tends to have a large variation of corrected torque when compared with clay. This is attributable to silt having a higher SPT$\mathrm{N}$ value than clayey soil. Hence, this shows that corrected torque is able to determine the strength of soil, thus classify different soil types [9].

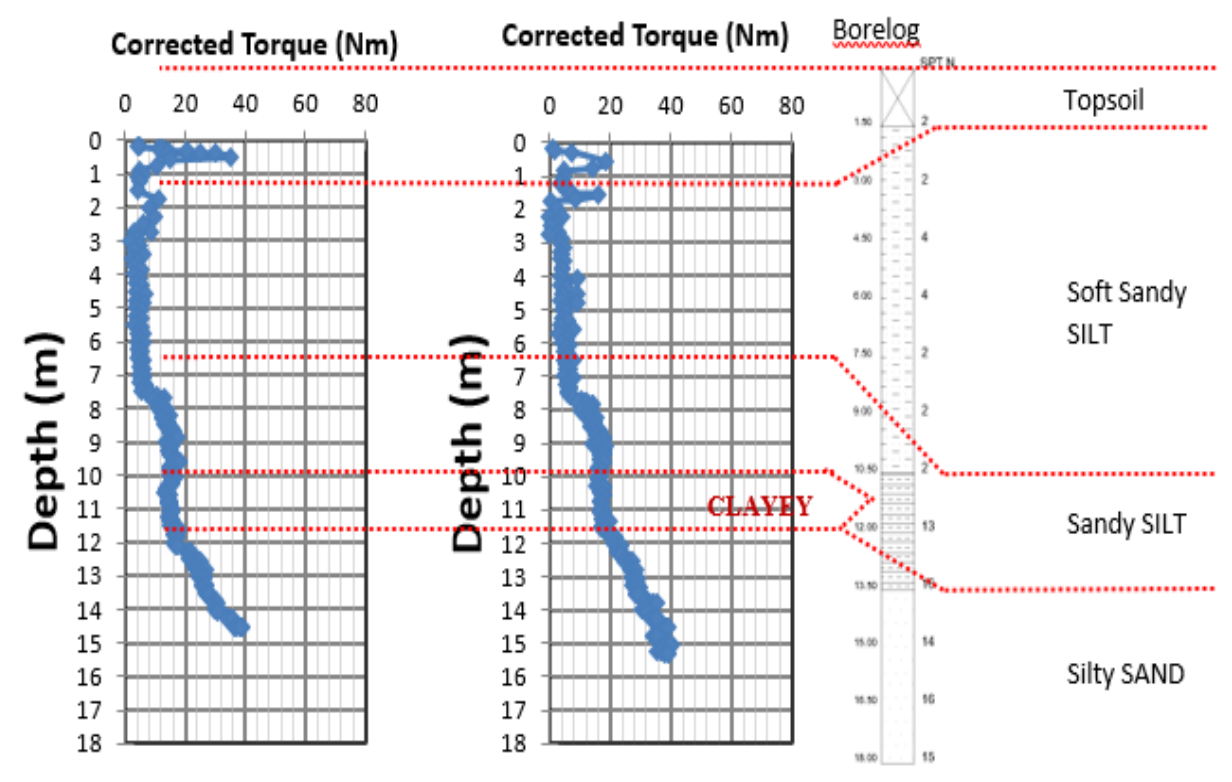

(a) 


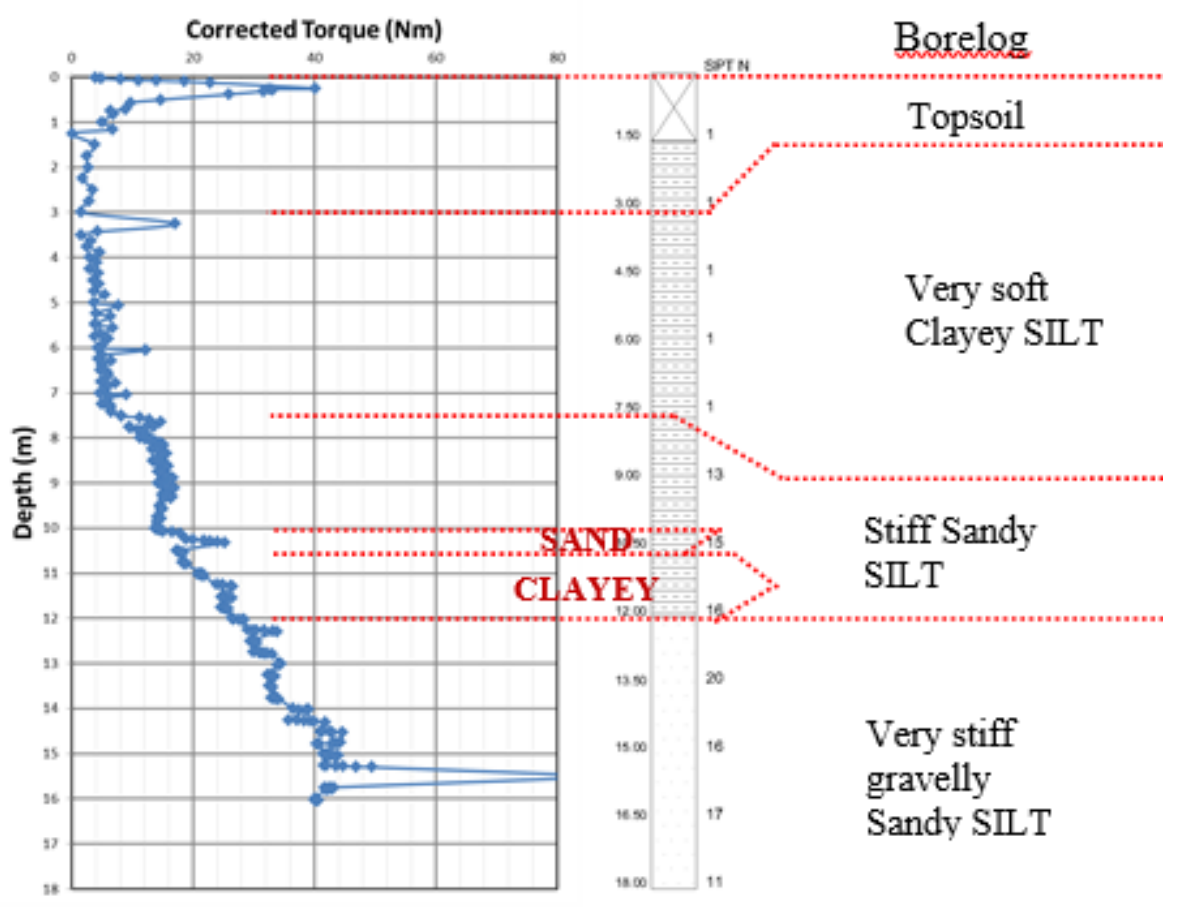

(b)

Fig. 4. Corrected torque from SDS tests and borelogs from deep boring tests for (a) BH1 and (b) BH2 from Batu Pahat site

Through the plots of corrected torque from SDS tests in Figure 4, generally five different soil layers could be identified, which are based on the range of corrected torque and the pattern occurred; 0 to $3 \mathrm{~m}, 3$ to $7.5 \mathrm{~m}, 7.5$ to $10.5 \mathrm{~m}, 10.5$ to $12 \mathrm{~m}$ and deeper than $12 \mathrm{~m}$. A potentially clayey layer is also detected between 10.5 to $12 \mathrm{~m}$. This is because the corrected torques are consistent with depth as normalised torque does not increase that much when corrected load increases. This shows that the soil is fine-grained and frictionless under undrained condition. Besides that, from SDS results shown in Figure 4(b), it can be seen at that a thin layer of sand is perceived between 10 and $10.5 \mathrm{~m}$ depth. At this layer, the value of corrected torque suddenly increased due to high friction as a result of the screw point going through the cohesionless soils. This phenomena recognised in SDS test has also been explained by [2]. Since this is a very thin layer, investigation through deep boring using SPT was not able to identify its existence.

The data obtained from SDS and SPT were correlated in order to determine a relationship between both tests. For this particular analysis, the Topsoil layer was not included in the analysis due to the soil had already been disturbed. Thus, this will affect the analysis greatly in a negative manner. The SPT-N value was correlated with the $\mathrm{E}_{0.25}$ data acquired from SDS which is similar to the method done by [10]. $\mathrm{E}_{0.25}$ is the penetration energy for every $25 \mathrm{~cm}$ penetration of screw [2]. The value is obtained by summing up the energy used in all the steps of loading in the $25 \mathrm{~cm}$ penetration through the soil layer. Based on Figure 5, it is found that the coefficient of determination, $\mathrm{R}^{2}$ for the correlation 
between SPT-N value and $\mathrm{E}_{0.25}$ is 0.725 (coefficient of correlation, $\mathrm{R}$ is 0.851 ) which shows that $72.5 \%$ of $\mathrm{E}_{0.25}$ is dependent on SPT-N. Hence this is considered as a very good correlation since SDS test result $\left(\mathrm{E}_{0.25}\right)$ is highly correlated with SPT-N values despite the limited data obtained from this site. From the linear regression analysis shown in Fig.5, the $\mathrm{E}_{0.25}$ is found to be correlated with SPT-N value $\left(\mathrm{N}_{\mathrm{SPT}}\right)$ as follows:

$$
\mathrm{E}_{0.25}=0.272 \mathrm{~N}_{\mathrm{SPT}}
$$

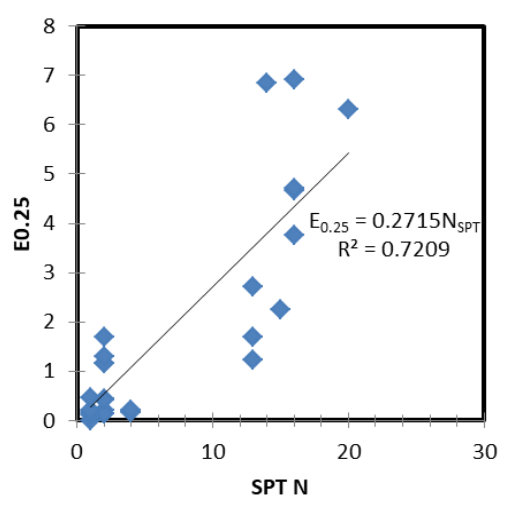

Fig. 5. Correlation between E 0.25 obtained from SDS test and SPT-N value for Batu Pahat site

From Eqn. (1), the SDS-N value could be estimated and the variation between SPT-N and estimated SDS-N values with depth for $\mathrm{BH} 1$ and $\mathrm{BH} 2$ is shown in Figure 6. From the figure, it could be observed that the trend of both values are similar. However, at about $8 \mathrm{~m}$ to $12 \mathrm{~m}$ depth, the SPT-N values for BH1 is less than the SDS-N values whereas it is the opposite for BH2. At these depths, the SPT-N values for BH2 are much higher than SDS-N values. Since SDS is an automatically operated test with the data being captured and stored automatically, mistakes in capturing and storing of data could be eliminated. Besides that obtained torque values are corrected based on rod friction. Hence, the deviation of the results is probably comes from the weakness of SPT test itself as also been pointed out by [2] and [13]. In using SPT-N values in design, many corrections have been suggested such as for actual energy delivered to the drill rod, for influence of overburden stress, to account for the length of the drill rod, to account for the absence of presence of a liner inside the split spoon sampler and to account for the influence of the diameter of the borehole. 


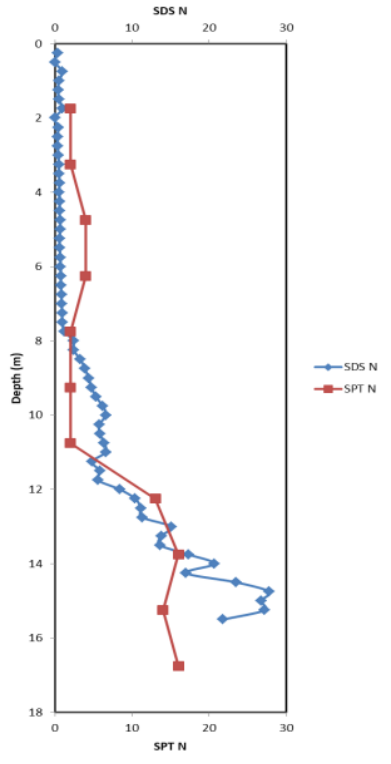

(a)

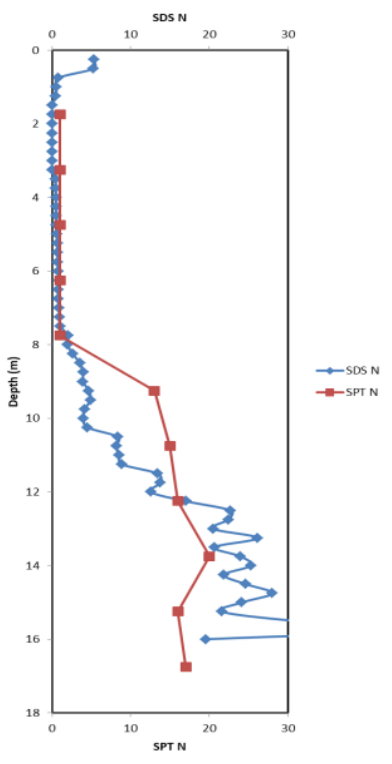

(b)

Fig. 6. Comparison between SPT-N and estimated SDS-N values for (a) BH1 and (b) BH2 at Batu Pahat site

\subsection{Correlation between SDS and MPT}

The data obtained from SDS tests at Cheras site was correlated with existing MPT data. Figure 7 shows a comparison of corrected torque (average of the two SDS tests) and MPT$M$ value. From the graph, it could be observed that the trend between corrected torque and $\mathrm{M}$ value for MP3 until $4 \mathrm{~m}$ depth is similar for both data. From Figure 7, it can be seen that the trend for MPT-M value of more than $4 \mathrm{~m}$ differs than corrected torque provided by SDS. The MPT-M value kept increasing while the corrected torque decreases then increases but not too significant after $6.75 \mathrm{~m}$ depth. It is well-known that MPT test is subjected to friction effect whereas this effect was removed in SDS test. Hence, it is wise not to consider the data beyond $4 \mathrm{~m}$ depth since by correlating both of these values obtained beyond $4 \mathrm{~m}$, it will affect the correlation. 


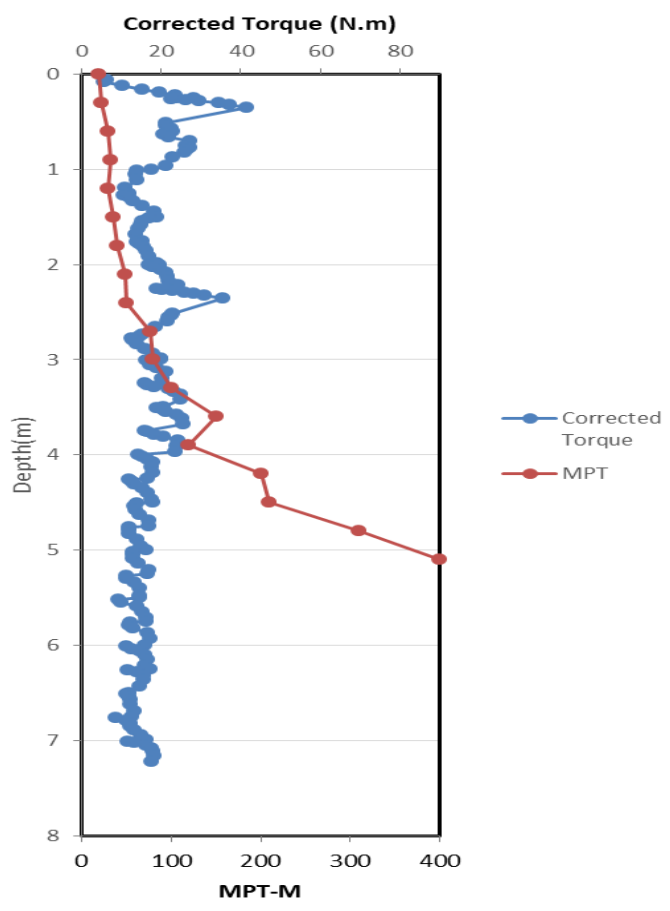

Fig. 7. Comparison of corrected torque from SDS test and MPT-M value at Cheras site

Figure 8 shows the relationship between MPT-M value and $\mathrm{E}_{0.25}$ from SDS test. The $\mathrm{R}^{2}$ value for correlation between both of these parameters is $0.851(\mathrm{R}=0.92)$, i.e., $85 \%$ of the $\mathrm{E}_{0.25}$ is dependent on the MPT-M value. This means $\mathrm{E}_{0.25}$ is highly correlated with MPT-M since the coefficient of correlation is $92 \%$, despite the limited data available. From the linear regression analysis shown in Fig.7, $\mathrm{E}_{0.25}$ is correlated with MPT-M value $\left(\mathrm{M}_{\mathrm{MPT}}\right)$ as follows:

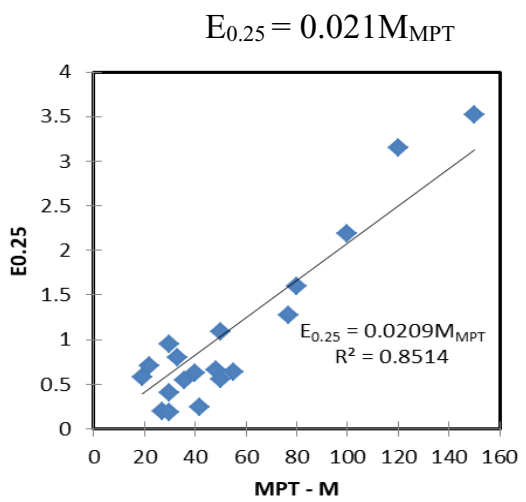

Fig. 8. Correlation between $\mathrm{E}_{0.25}$ obtained from SDS test and MPT-M value at Cheras site

From Eqn. (2), the SDS-M value could be estimated and the variation between MPT-M and estimated SDS-M values with depth is shown in Figure 9. From the figure, it can be observed that both values are similar, particularly up to $4 \mathrm{~m}$ depth in which as the value of MPT-M increase, the SDS-M would also increase with depth. However, beyond $4 \mathrm{~m}$ depth, 
MPT-M values increases with depth but SDS-M values decreases up to $6.25 \mathrm{~m}$, and increased thereafter. As a preliminary findings, it could be deduced that the results from SDS and MPT are best correlated for shallow depth. This however could be improved in the future if more data are available to be correlated.

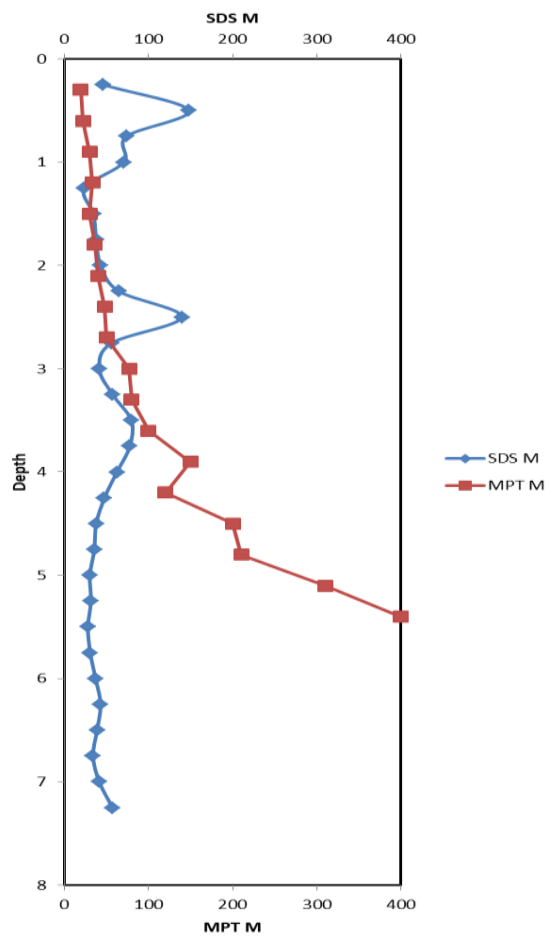

Fig. 9. Comparison between MPT-M and estimated SDS-M values at Cheras site

\section{Conclusion and recommendations}

Screw driving sounding test (SDS) is a newly developed soil investigation method which is an improved version of Swedish Weight Sounding (SWS). Parameters that could be measured from SDS are applied load, maximum torque, average torque and minimum torque on rod, penetration length, penetration velocity and number of rotations. In comparison, SDS could possibly replace other conventional soil investigation method as it is fast, cheap and does not require highly skilled workers. Besides that SDS tests can give quality results from the usage of technology from the Industrial Revolution 4.0.

An attempt has been made to carry out SDS tests at various sites in Malaysia to investigate if SDS test results could be correlated with the results from Standard Penetration Test (SPT) and Mackintosh Probe Test (MPT). These SPT and MPT are in-situ tests in soil investigation work that are widely implemented in Malaysia. Based on the analysis done it is found that both the SPT and MPT are highly correlated with SDS. This is based on the coefficient of determination $\left(\mathrm{R}^{2}\right)$ values of greater than 0.7 , i.e. coefficient of correlation $(\mathrm{R})$ of greater than 0.84 , were obtained, although using limited data from two test sites only. More results are needed in order to refine and increase the accuracy of the correlation between SPT-N and SDS-N, and MPT-M and SDS-M for soils in Malaysia. Soil classification chart for Malaysian soils is also another significant result that could be developed in future from SDS test results. Hence, in order to achieve that, more SDS tests on Malaysian soils is recommended to be carried out that need the support from 
government and private agencies involved in construction industry to ensure CITP 20162020 will be achieved as planned.

\section{Acknowledgement}

The authors gratefully acknowledge the financial support and contribution given by the Japan Home Shield Corporation through the Research Contract No. 4C134, in undertaking this research. Special acknowledgements are conveyed to Dr. Nor Zurairahetty Mohd Yunus, Madam Fauziah Kasim, Dr. Siti Norafida Jusoh and Assoc. Prof. Dr. Kamarudin Ahmad from the Faculty of Civil Engineering, UTM for their assistance in this research. The help from the students; Muhammad Hatta Satar, Muhammad Mustaqim Ponimin and Mohd Fakrulnizam Mohd Tahir, as well as Assistant Engineer, Razale Mohamed are also greatly appreciated.

\section{References}

1. H. Wazoh and J. Mallo, "Standard Penetration Test in Engineering Geological Site Investigations - A Review," Int. J. Eng. Sci., pp. 1813-2319, (2014)

2. S.Y. Mirjafari, R. P. Orense, and N. Suemasa, "Soil classification and liquefaction evaluation using Screw Driving Sounding," Proc. 5th Int. Conf. Geotech. Geophys. Site Characterisation, ISC 2016, 1, 2001, pp. 284-286, (2016)

3. A. Fakher, M. Khodaparast, and C.J.F.P. Jones, "The use of the Mackintosh Probe for site investigation in soft soils," Q. J. Eng. Geol. Hydrogeol., 39, 2, pp. 189-196, (2006)

4. S.F. Chan and F.K. Chin, "Engineering characteristics of the soil along the federal highway in Kuala Lumpur. Proceeding of the Third Southeast Asian Coference on Soil Engineering, Hong Kong, $41-45$, (1972)

5. C.R.I. Clayton, N.E. Simons, and M.C. Matthew, Site Investigation 2nd Edn, Blackwell Science, Oxford. (1995)

6. S.Y. Mirjafari, R. P. Orense, and N. Suemasa, Comparison Between CPT and SDS Data for Soil Classification, pp. 561-566, (2013)

7. U. Bergdahl, B.B. Broms, and T. Muromachi, "Swedish Weight Sounding Test : International Reference Test Procedure "Penetration Testing, ISOPT-1(ed.), A.A Balkema Inc., 71-90 (1988)

8. B.B. Broms and N. Flodin, "History of Soil Penetration Testing" Penetration Testing, A.A Balkema Inc. (1988)

9. T. Tanaka, N. Suemasa, and S. Yamato, "Assessment of Soil Characteristics by Screw Driving Sounding," 19th Southeast Asian Geotech. Conf. 2nd AGSSEA Conf. (19SEAGC 2AGSSEA) Kuala Lumpur, pp. 3-6, June, (2016)

10. T. Tanaka and N. Suemasa, "Classification of Strata Using Screwdriver Sounding Test,” Int. Soc. Offshore Polar Eng., 4, pp. 851-856, (2012)

11. S.Y. Mirjafari Miandeh, "Soil Characterisation using Screw Driving Sounding (SDS) data", PhD Thesis, University of Auckland, New Zealand, (2016)

12. N. Suemasa, K. Shinkai, T. Suzawa and M. Tamura, A plasticity Model for Swedish Weight Sounding Test. Proc. 4th Japan-Philipinnes Workshop on Safety and Stability of Infrastructure, University of Philipinnes, 169-177, (2005) 
13. J.D. Rogers, "Subsurface Exploration using the Standard Penetration Test and the Cone Penetrometer Test", Journal of Environmental Engineering and Geoscience, 12, 2, pp 161-179, (2006) 